\title{
Minimally invasive spine surgery in the treatment of thoracolumbar and lumbar spine trauma
}

\author{
Theodore KoreckiJ, M.D., Daniel K. Park, M.D., and Jeffrey Fischgrund, M.D. \\ Department of Orthopaedic Surgery, William Beaumont Hospital, Royal Oak, Michigan
}

\begin{abstract}
Thoracolumbar and lumbar trauma account for the majority of traumatic spinal injuries. The mainstay of current treatments is still nonoperative therapy with bracing. Classic treatment algorithms reserved absolute surgical intervention for spinal trauma patients with neurological compromise or instability. Relative indications included incapacitating pain and obesity/body habitus making brace therapy ineffective. In the past decade, minimally invasive surgical (MIS) techniques for spine surgery have been increasingly used for degenerative conditions. These same minimally invasive techniques have seen increased use in trauma patients. The goal of minimally invasive surgery is to decrease surgical morbidity through decreased soft-tissue dissection while providing the same structural stability afforded by classic open techniques. These minimally invasive techniques involve percutaneous posterior pedicle fixation, vertebral body augmentation, and utilization of endoscopic and thoracoscopic techniques. While MIS techniques are somewhat in their infancy, an increasing number of studies are reporting good clinical and radiographic outcomes with these MIS techniques. However, the literature is still lacking high-quality evidence comparing these newer techniques to classic open treatments. This article reviews the relevant literature regarding minimally invasive spine surgery in the treatment of thoracolumbar and lumbar trauma.
\end{abstract} (http://thejns.org/doi/abs/10.3171/2014.5.FOCUS1494)

KEY WoRds
thoracolumbar

I NJURIES to the thoracolumbar and lumbar spine account for the majority of traumatic spine injuries.9,51 These injuries can involve compression fractures, burst fractures, flexion-extension injuries (that is, Chance fractures), dislocations, and any combination thereof. In the presence of neurological injury, few would argue that surgical treatment is indicated. However, controversy arises in those cases in which patients are neurologically intact. Wood et al. have demonstrated that in neurologically intact patients operative management of thoracolumbar burst fractures provided little benefit at 4 years posttreatment compared to treatment with a brace..$^{51}$ However, neurologically intact patients who present with significant spinal deformity or who are at risk of developing significant deformity, have incapacitating pain, or are unable to tolerate brace treatment still represent a treatment dilemma.

In recent years, several minimally invasive surgical (MIS) techniques have been developed to instrument the spine. The goal of MIS procedures is to achieve the same results as traditional open surgery while limiting the morbidity. The goals are to achieve spinal stability, re-

\footnotetext{
Abbreviations used in this paper: $\mathrm{CPC}=$ calcium phosphate cement; MIS = minimally invasive surgical; PMMA = polymethylmethacrylate; PPSI $=$ percutaneous pedicle screw instrumentation; VAS $=$ visual analog scale.
}

store alignment, and return function. Three common MIS techniques that have been used in trauma patients include percutaneous pedicle screw instrumentation, kyphoplasty/vertebroplasty augmentation, and lateral transpsoas fusion techniques. The aim of this systematic review was to examine the current literature available on the use of MIS techniques in the treatment of thoracolumbar and lumbar spine trauma.

A PubMed search, utilizing the key words "minimally invasive surgery," "percutaneous pedicle screw," "kyphoplasty," "vertebroplasty," and "transpsoas/direct lateral approach" together and alone in combination with "thoracolumbar trauma" and "spine trauma," was used initially in our literature search. After a review of the abstracts by the authors independently, the articles deemed relevant to the topic at hand were used. Due to a paucity of Level 1 evidence, both prospective and retrospective case-control studies, as well as case reports, were included in this review. Exclusionary criteria included a patient study population not involving traumatic injuries of the thoracolumbar spine, lack of clinical follow-up, and age less than 18 years.

\section{Percutaneous Pedicle Screw Instrumentation}

Percutaneous pedicle screw instrumentation (PPSI) has been in development for more than 10 years $^{6}$ (Fig. 
1). The goal of PPSI is to decrease the trauma associated with the standard open approach, which can lead to significant devascularization and denervatation of the paraspinal musculature. ${ }^{15,16,38}$ This tissue trauma may be a contributing factor to patients' chronic pain after surgery (so-called fusion disease). In a cadaveric study, PPSI was shown to spare the motor nerve to the multifidus muscle $80 \%$ of the time whereas standard approaches were shown to require transection of the nerve $84 \%$ of the time. ${ }^{39}$ In a MRI-based study, Kim et al. highlighted reduced muscle atrophy associated with the use of PPSI compared with a standard open approach. ${ }^{19}$

A number of studies have been published on the use
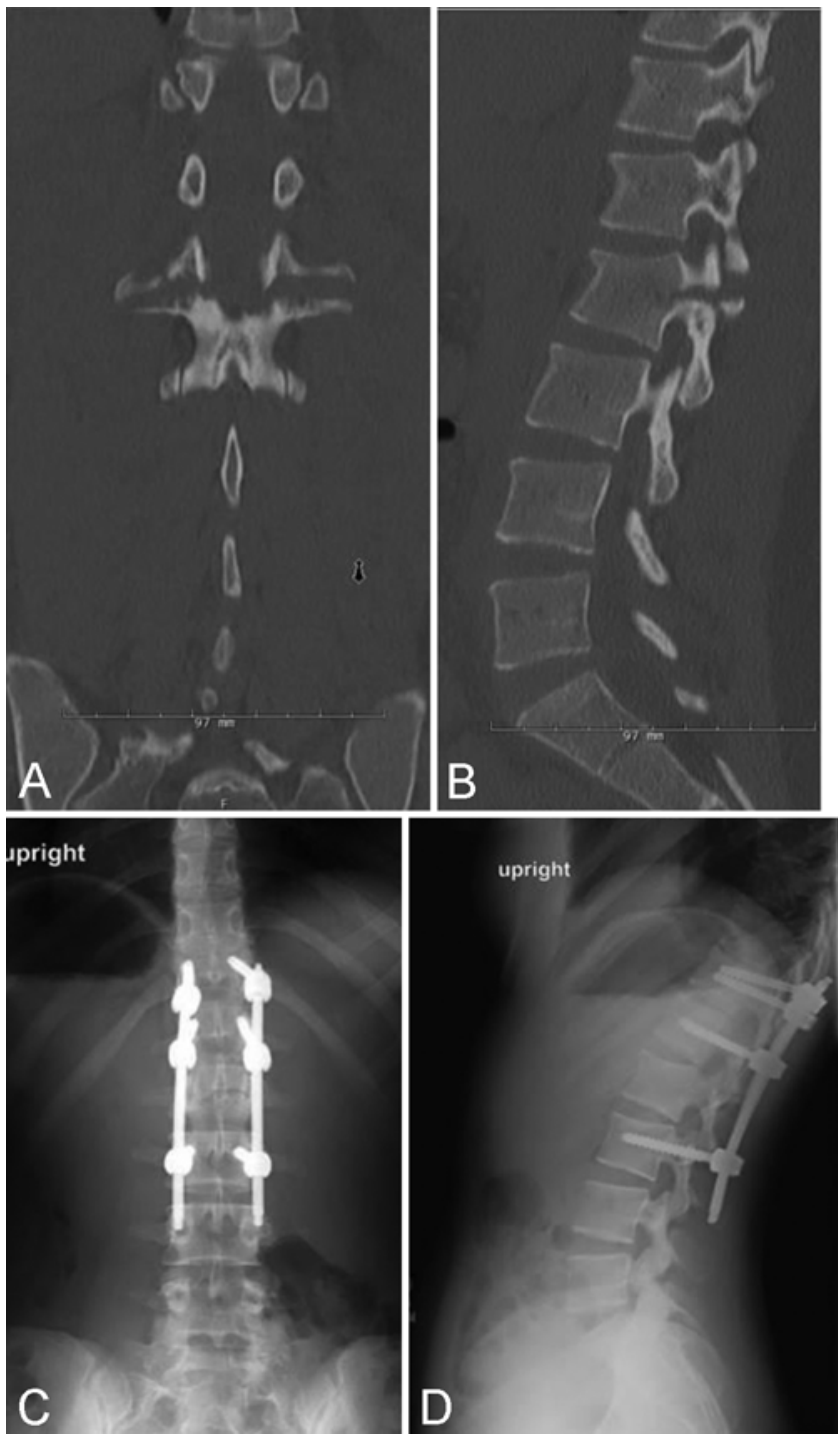

FIG. 1. Reconstructed CT scans and radiographs obtained in a 17 -year-old girl who suffered a flexion-distraction injury at L-2. Due to intractable pain, she was unable to walk despite brace therapy. A and B: The CT scans demonstrate bilateral pedicle fractures with gapping of the posterior bony elements on coronal view (A). A right parasagittal view is also shown to demonstrate the fractures (B). Reduction of the fracture site was obtained with a combination of intraoperative positioning and percutaneous compression over the rod at the fracture site. C and D: Radiographs were acquired 6 weeks after a percutaneous pedicle stabilization. of PPSI in thoracolumbar trauma. Percutaneous pedicle screw instrumentation has been used to treat various trauma patterns. In a study of 21 patients with thoracolumbar compression injuries (Type A3 according to Magerl/AO classification) without neurological deficits, Wild et al compared factors in those treated PPSI or standard open pedicle instrumentation. ${ }^{50}$ The PPSI-treated patients had significantly less intraoperative blood loss but operative time was longer. There was no difference in radiographic or clinical outcomes 5 years after implant removal. Wang et al. ${ }^{46}$ reported on 38 patients with similar injuries for whom the average follow-up was 11.6 months. ${ }^{31}$ They found significant decreases in blood loss, operative time, hospital stay, blood transfusions, proportion of antalgic supplement, and postoperative incisional visual analog scale (VAS) pain score between the 2 groups, in favor of PPSI. Vanek et al. recently published a prospective study comparing outcomes after PPSI compared with standard open surgery in 35 patients with thoracolumbar burst fractures (Type A3 of Magerl/AO classification). ${ }^{43}$ The authors used short-segment fixation (fixation 1 level above and below the injury) in patients without neurological deficits. Those patients treated with PPSI had significantly shorter operative times, less blood loss, and less postoperative pain. Radiographic and clinical outcomes at 2-year follow-up were not significantly different between the 2 groups. These findings have been echoed in a number of retrospective series published on PPSI used in the treatment of compression/burst-type thoracolumbar and lumbar fractures. ${ }^{2,24}$

While these previous studies retrospectively analyzed 2 patient cohorts, Jiang et al. recently published the only prospective randomized control trial comparing PPSI to an open paraspinal approach for thoracolumbar burst fractures in patients without neurological deficits. The authors demonstrated significant decreases in blood loss associated with PPSI compared to the paraspinal approach ( $79 \mathrm{ml}$ vs $145 \mathrm{ml}$, respectively), a shorter hospital stay (9.7 vs 10.8 days, respectively) and less pain postoperatively. ${ }^{13}$ After more than 3 years of follow-up of 61 patients, there were no differences in Oswestry Disability Index score or VAS score. The paraspinal muscle group was able to achieve and maintain sagittal correction better than those obtained by the PPSI group. The authors concluded that PPSI offers improvements over the paraspinal approach. However, they cautioned against the use of PPSI in those patients in whom a postural reduction is not achieved on the operating room table; a more open approach may be desirable to achieve improved fracture reduction and deformity correction.

Furthermore, Grossbach et al. also used PPSI in cases of flexion-distraction injuries and found similar benefits. Patients who underwent PPSI had significantly less blood loss those who underwent a standard open approach and was a trend toward shorter operative times in the former group as well. Radiographic outcomes did not differ between groups at a mean follow-up of 18.5 months. ${ }^{10}$

Furthermore, percutaneous techniques are being applied to pelvic fixation as well. Wang et al. described a percutaneous iliac screw technique in the treatment of an L-5 burst fracture. ${ }^{47}$ Alar iliac fixation of S-2 is also gain- 
ing popularity as a form of pelvic fixation. O'Brien et al. published a cadaveric study demonstrating the feasibility of percutaneous placement of S-2 alar iliac screws. ${ }^{32}$ Computed tomography scans revealed that no screw put any visceral or neurovascular structure at risk and no screw violated the cortex of the ilium. A recent report of 2 patients, one with a large lytic sacral lesion and the other with an H-type sacral fracture, described the successful clinical application of this technique. ${ }^{26}$ Although clinical evidence is limited and no data can be gleamed regarding outcomes or reductions in morbidity with these techniques, they will undoubtedly be seen again and may ultimately prove useful in a spine surgeon's MIS armamentarium.

However, percutaneous instrumentation is not without risks and complications. In a study of 424 percutaneously placed pedicle screws, postoperative CT scans demonstrated 41 misplaced screws $(9.7 \%)$. Lateral cortical breaches were more common $(n=30)$ than medial breaches $(n=11)$, and neurological injury as a result of these breaches occurred with 2 screws $(0.5 \%) .{ }^{37}$ In an earlier study of 404 percutaneous pedicle screws, Wiesner et al. reported a misplaced screw rate of $6.6 \%$. The most common site of screw misplacement was at the S-1 level. Neurological injury occurred with the misplacement of one screw but resolved fully upon removal of the screw. ${ }^{49}$ Additional complications can arise in association with the guidewire used in the placement of cannulated percutaneous screws. Mobbs and Raley reported 7 guidewire perforations of the anterior vertebral body in 525 percutaneously placed screws: 2 cases due to inadvertent advancement of the K-wire at the time of tapping the pedicle, 2 due to poor tactile feedback for the surgeon owing to osteoporotic bone, and 1 due to too forceful advancement of the guidewire. Two patients developed postoperative ileus and had a small retroperitoneal hematoma noted on CT scanning. ${ }^{30}$

Central to the debate of minimally invasive surgery for trauma is the need for fusion in these patients. In a prospective study of 58 patients with thoracolumbar burst fractures, Wang et al. compared fusion versus instrumentation without fusion, and noted that results in a 41-month follow-up period were equivocal. Loss of vertebral body height correction, segmental motion, intraoperative estimated blood loss, and operative time were significantly worse in the fusion group than the nonfusion group. ${ }^{48}$ However, none of these differences translated to a difference in clinical outcome scores. Lee et al. compared factors in 59 patients undergoing PPSI to those derived from a historical cohort of patients who underwent fusion at the authors' institution; they found no differences in postoperative correction loss between the groups at the final follow-up. Clinical results showed that the PPSI-treated patients had quicker improvements in pain and clinical outcomes measures, but the results of each treatment were equivalent at final follow-up. ${ }^{24}$ In both of these studies, posterior ligamentous injury was not an exclusion criterion, but no details regarding outcomes of those patients undergoing PPSI in the setting of posterior ligamentous injury were given. Yang et al. reported on 57 thoracolumbar burst fractures treated without fusion and implant removal at 9-12 months. They noted, when implants were removed, a significant loss in the postoperative kyphosis correction, although it remained significantly improved compared with the initial injury kyphosis. However, this loss of correction following implant removal did not correlate with worsening clinical outcomes in an average follow-up of 40 months. ${ }^{52}$ This study, however, excluded patients with posterior ligamentous injury.

The clinical question of whether a fusion is needed in all thoracolumbar trauma cases is still unsolved. In a randomized prospective trial comparing short-segment (1 level above and 1 below the fracture) pedicle screw fixation with and without posterolateral fusion for thoracolumbar burst fractures, Dai et al. demonstrated equivalent outcomes in regard to loss of kyphosis correction in 73 patients at a minimum of 5 years postoperatively. Importantly, the authors included only those burst fractures that scored less than 6 points on the Load Sharing Classification score (discussed later). Although PPSI was not used in this particular study, the study represents high-level evidence refuting the necessity of fusion in a certain subset of thoracolumbar burst fractures. ${ }^{3}$ These studies, as well as those mentioned in the earlier paragraphs, appear to show good short- to midterm outcomes with PPSI. However, when considering fusion versus nonfusion, the effect of posterior ligamentous injury on outcome in PPSI-treated patients is unknown and should be controlled for in future studies. Additionally, long-term studies will be necessary to settle this debate, particularly as it relates to need for further surgery for adjacent-level disease in fusion patients.

Despite these ongoing debates surrounding the use of PPSI, the senior authors (D.P. and J.F.) will use this technique in selected trauma patients (Fig. 2). In patients without neurological compromise and with a pure bony injury without ligamentous disruption, they will use PPSI without fusion should the fracture demonstrate instability or if a patient is not amenable to wearing a brace. However, in cases of posterior ligamentous disruption and a significant deformity that cannot be reduced by patient positioning and closed reduction, they would opt for standard approaches and fusion or PPSI with facet fusions. When the status of the posterior ligamentous complex is equivocal or indeterminate, PPSI without fusion is more likely to be used, particularly in the young active patient cohort. Implant removal is typically undertaken 9 months postoperatively.

\section{Percutaneous Anterior Column Augmentation}

Another trend in MIS techniques has been decreasing the amount of instrumentation needed to achieve a stable spine. Standard open approaches typically involved instrumentation of 2 levels above and 2 levels below the fracture, ${ }^{45}$ however, so-called short-segment fixation (instrumentation 1 level above and 1 level below the fracture) has been attempted with varying degrees of success in traditional spine surgery. The first published attempts at short-segment fixation met with unacceptably high failure rates. Kramer et al. reported hardware failure in 4 of 11 thoracolumbar fractures treated with short-segment fixation performed via a standard open approach with posterolateral fusion within a 2 -year follow-up. ${ }^{23}$ In a 

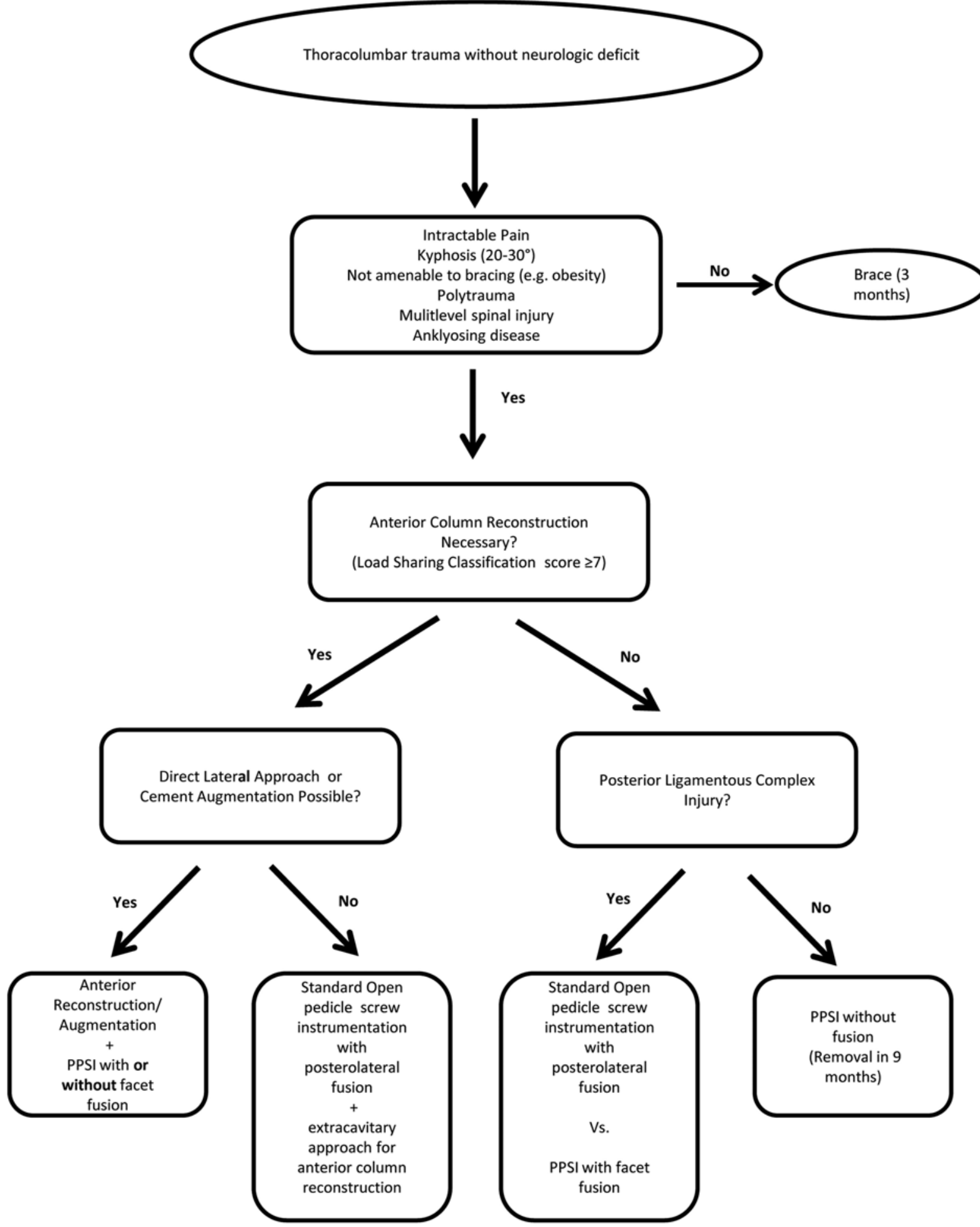

FıG. 2. Algorithm used by authors in the treatment of patients with thoracolumbar trauma.

study of 52 thoracolumbar fractures treated in a similar fashion, McLain et al. reported on failure of the fixation construct in 10 patients in whom the failure manifested as progressive kyphosis due to the bending of screws, kyphosis resulting from osseous collapse or vertebral translation without hardware failure, or segmental kyphosis after screw breakage. ${ }^{28}$ The authors stated that untreated anterior stability resulted in unacceptable high failure rates when used in combination with short-segment fixation. Biomechanical studies have shown that short-segment fixation without anterior support can restore axial stiffness to only $75 \%$ of that of an intact lumbar spine. ${ }^{11}$ 
The poor results with short-segment fixation alone highlighted the importance of anterior support. McCormack et al. reviewed 28 cases of thoracolumbar burst fracture treated with posterior pedicle fixation. They developed the Load Sharing Classification system to predict failure of posterior fixation alone in the treatment of anterior column fractures. The classification system contains 3 separate factors of fractured vertebrae to determine whether anterior support is necessary: vertebral body communition, apposition of the fracture fragments, and the amount of correction of kyphotic deformity. Each factor is awarded 1,2, and 3 points (mild, moderate, and severe) for a maximum score of 9 points overall. According to the system, fractures scoring 7 or more points require anterior reconstruction to prevent posterior hardware failure. ${ }^{27}$ Prospective utilization of the Load Sharing Classification in the treatment of thoracolumbar trauma has shown it to be a useful tool in determining the need for anterior column support. ${ }^{1,3,34}$

However, anterior surgery is technically demanding and associated with an increased rate of morbidity. ${ }^{14,20,21}$ To decrease the morbidity associated with anterior surgery, several authors have used percutaneous transpedicular kyphoplasty to provide anterior support in the treatment of thoracolumbar fractures while avoiding the associated morbidity of an open procedure. Biomechanically, Mermelstein and coworkers demonstrated that vertebral body augmentation, with calcium phosphate cement (CPC), of an L-1 burst fracture cadaveric model reduced pedicle screw flexion and extension bending moments by $59 \%$ and $38 \%$, respectively. ${ }^{29}$ The ability to percutaneously augment vertebral body fractures has renewed interest in short-segment fixation.

Korovessis et al. published an article on 18 patients with severe compression and lumbar burst fractures treated with balloon kyphoplasty, CPC augmentation, and short-segment fixation; the mean follow-up was 22 months. ${ }^{22}$ The mean blood loss and operating time were 45 minutes and $75 \mathrm{ml}$, respectively. Segmental kyphosis improved from $16^{\circ}$ preoperatively to $2^{\circ}$ postoperatively without loss of correction throughout the follow-up period. Clinical outcome measures improved significantly, and no neurological complications were encountered. Verlaan and associates used balloon kyphoplasty and CPC augmentation in combination with short-segment pedicle screw fixation to treat thoracic and lumbar burst fractures in 21 patients and reported similar results in terms of improvement in clinical outcome measures. ${ }^{44}$ Again, the procedure was well tolerated and no neurological sequelae were encountered despite extravasation in 6 patients. A $21 \%$ increase in anterior vertebral height was obtained postoperatively. However, the only radiological measurements were those obtained 1 month after surgery.

Fuentes et al. used percutaneous vertebral body augmentation with polymethylmethacrylate (PMMA) cement and short-segment PPS fixation in the treatment of 18 thoracolumbar burst fractures. ${ }^{7}$ Patients were followed up for an average of 26 months. Patients tolerated the procedure well and the authors reported a significant reduction in VAS scores and a 4.5-day average hospital stay. The kyphotic angle was $11^{\circ}$ immediately after surgery but there was an average loss of $2^{\circ}$ at final follow-up. No hardware failures were encountered. Rahamimov et al. conducted a similar study in 52 patients with thoracolumbar compression and burst fractures; the authors used percutaneous augmentation with PMMA and short-segment PPS fixation. ${ }^{36}$ However, the pedicle screw fixation was additionally augmented with PMMA. The authors reported an estimated blood loss of less than $50 \mathrm{ml}$ in $77 \%$ of patients and an average operating time of 121 minutes. At 1-year follow-up, radiographic studies showed a $3^{\circ}$ loss in correction compared with those obtained in the immediate postoperative period. The authors reported 3 cases of PMMA emboli, and in half of the patients there was a cement leak into adjacent soft tissue either through the fracture or through segmental veins but no cases of extravasation into the spinal canal.

Some authors have even tried these percutaneous techniques without posterior instrumentation. Maestretti et al. used percutaneous augmentation with CPC alone without posterior stabilization in the treatment of thoracolumbar compression and burst fractures. ${ }^{25}$ Inclusion criteria included fracture with at least $15^{\circ}$ of kyphosis in patients with a single traumatic injury or $10^{\circ}$ in those with more than one traumatic injury or with multilevel fractures without any neurological deficit. The authors reported good outcomes with a standalone procedure both clinically and radiographically. However, they cautioned against the use of standalone percutaneous augmentation with CPC in cases involving severe fractures, due to the poor shearing stability of this biological material.

\section{Thoracoscopic/Endoscopic and Direct Lateral Anterior Column Reconstructions}

Another trend in minimally invasive surgery is utilizing thoracoscopic/endoscopic approach to the spine and direct lateral anterior column reconstruction. As stated previously, standard open thoracoabdominal approaches to the anterior column are not without significant morbidity. ${ }^{5,45}$ In the reviews by Faciszewski et al. ${ }^{5}$ and Verlaan et al., ${ }^{45}$ anterior procedures in the thoracic and lumbar spine were associated with complication rates of $15 \%-20 \%$. Included in the risk profile were pneumo-/ hemothorax, sympathetic dysfunction, bowel injury, ileus, vascular injury, diaphragmatic herniations, and significant thoracotomy-associated pain. To minimize the morbidity of a thoracotomy, thoracoscopic techniques used in cardiothoracic surgery have been purposed. Kim et al. reported their results for thoracoscopic decompression, reconstruction, and instrumentation in 212 patients with Type A, B, or $\mathrm{C}$ fractures (according to the AO/Magerl classification). ${ }^{18} \mathrm{~A}$ majority of patients (64\%) additionally underwent standard open posterior stabilization, with all attempts at deformity correction occurring at the time of posterior instrumentation, and the remaining patients undergoing standalone cage and lateral instrumentation placement. With this strategy, the authors were able to perform complete corpectomy and cage placement as far as L-2. The authors reported an $85 \%$ fusion rate for the standalone procedures and a greater than $90 \%$ fusion rate 


\section{T. Koreckij, D. K. Park, and J. Fischgrund}

at 1 year for combined procedures. In $90 \%$ of patients, preoperative sagittal alignment was maintained at final follow-up. Complications included conversion to an open procedure in 3 cases, implant loosening in 5, and pleural effusion, postoperative neuralgia, and pneumothorax in 12. Khoo et al. used the thoracoscopic approach on 371 patients with $73 \%$ of the fractures located at the thoracolumbar junction. ${ }^{17}$ They reported a steep learning curve but a low severe complication rate $(1.3 \%)$. In a comparison with standard open approaches, thoracoscopic surgery reduced postoperative analgesic requirements by $42 \%$.

Use of the transpsoas or lateral approach to the lumbar and thoracolumbar spine has been increasing over the last decade in the treatment of degenerative conditions ${ }^{12,40}$ (Fig. 3). Smith et al. used this approach in the treatment of 52 patients with rotation- and distraction-type (AO/Magerl Type B and C) fractures. ${ }^{41}$ Using this approach, the authors achieved anterior column support with expandable titanium cages followed by anterolateral fixation or pedicle screw fixation or a combination thereof. In cases of posterior pedicle instrumentation, short-segment fixation was used $75 \%$ of the time. The mean operative time was 127 minutes and the mean estimated blood loss was $300 \mathrm{ml}$. The authors reported a complication rate of $15 \%$, which included 2 cases of dural tears, 2 cases of intercostal neuralgia, 2 cases of deep vein thrombosis, 1 case of pleural effusion, and 1 case of infection. Several case reports in the literature have also demonstrated success when utilizing this technique in cases of thoracolumbar and lumbar trauma.4,42

There are approach-specific complications associated with the lateral or transpsoas approach. This approach can place the exiting lumbar nerve roots and lumbosacral plexus at risk. In a cadaveric study, Park et al. described the paths of the intervertebral nerves and the lumbosacral plexus as they traverse the psoas muscle in relation to the center of the intervertebral disc. The authors expressed caution when approaching the lumbar spine via a trans- psoas approach, particularly at more distal levels where nerves are found to be at increased risk for injury crossing the intervertebral disc near its midpoint. ${ }^{33}$ In clinical reports, the most common complication is transient thigh numbness, pain, or weakness, the incidence of which ranges from $1 \%$ to $60 \% .{ }^{35}$ There has also been a case report of an incisional hernia associated with this approach, with the authors recommending that an incision be made as far posterior as possible and that blunt dissection be used to avoid denervation of the abdominal musculature. ${ }^{8}$

\section{Conclusions}

No clear consensus exists regarding the best way to treat thoracolumbar and lumbar trauma. The decisionmaking process must take into account fracture stability, neurological status (either compromised or having the potential to become compromised), polytrauma, the likelihood of success with nonoperative management, and overall experience of the surgeon. Historically, the surgical treatment of thoracolumbar and lumbar fractures consisted of open long-segment posterior fixation with or without anterior surgery, depending on fracture morphology. While successful, these extensive open procedures are not without significant morbidity. With the advent and success of MIS procedures in the treatment of degenerative spinal pathologies, there has been increased adaptation of these techniques to treat spinal trauma. Percutaneous pedicle fixation and percutaneous anterior column augmentation (that is, kyphoplasty) have seen the most widespread application. Thoracoscopic and endoscopic procedures, with large learning curves and techniques foreign to most spine surgeons, have been less enthusiastically embraced. Mini-open approaches (that is, lateral and transpsoas approaches) are also being use more commonly in treating spinal pathologies.

The literature does appear to support the idea that these less invasive techniques afford less patient mor-
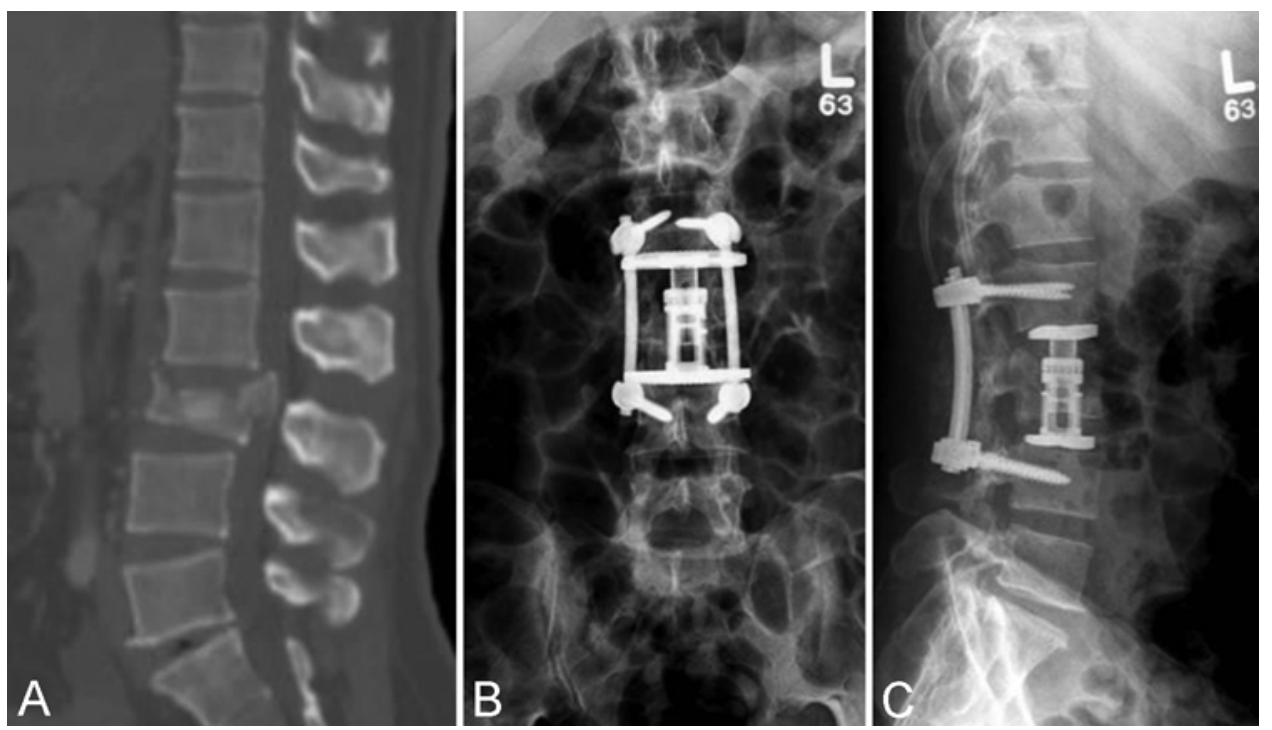

FIG. 3. Studies obtained in a 58-year-old patient. A: Parasagittal CT scan showing an L-3 burst fracture without neurological compromise. B and C: At 3 months after a direct lateral approach for corpectomy and reconstruction with posterior mini-open pedicle screw fixation, as shown in upright anteroposterior and lateral radiographs. 
bidity, and, at least in the short term, these techniques appear to be successful in treating most thoracolumbar and lumbar trauma. Unfortunately, the literature regarding the use of these techniques lacks high-level evidence and exists mainly in the form of retrospective case series. The current body of literature frequently contains a wide spectrum of traumatic injuries (for example, injured or uninjured posterior ligamentous complex, anterior column injuries of varying severity, and so on), which makes drawing conclusions regarding the treatment of any one fracture entity difficult. Although radiographic criteria were frequently used as end points in the previously described studies, these end points fall well short of allowing us to determine the ultimate utility of a treatment modality. Also of paramount importance to this topic is the assessment of adequate fusions; although CT scanning represents the gold standard, few studies in the trauma population have been reported to date. Moving forward, future studies should make use of validated functional outcomes measures in a well-defined cohort of patients. Long-term follow-up will also be necessary to determine if these newer modalities can withstand the tests of time and if standard long-segment fusions present with untoward complications related to adjacent-segment disease compared with nonfusion treatment options. Minimally invasive surgery in the spine holds significant promise but the current body of evidence is mediocre at best and leaves many questions yet unanswered.

\section{Disclosure}

Dr. Park is a consultant for K2M, Stryker, Baxano, and DePuy. Dr. Fischgrund is a consultant for Stryker and Relievant and holds stock in Baxano Surgical.

Author contributions to the study and manuscript preparation include the following. Conception and design: Koreckij, Park. Acquisition of data: Koreckij, Park. Analysis and interpretation of data: all authors. Drafting the article: all authors. Critically revising the article: all authors. Reviewed submitted version of manuscript: all authors.

\section{References}

1. Aligizakis AC, Katonis PG, Sapkas G, Papagelopoulos PJ, Galanakis I, Hadjipavlou A: Gertzbein and load sharing classifications for unstable thoracolumbar fractures. Clin Orthop Relat Res (411): 77-85, 2003

2. Court C, Vincent C: Percutaneous fixation of thoracolumbar fractures: current concepts. Orthop Traumatol Surg Res 98:900-909, 2012

3. Dai LY, Jiang LS, Jiang SD: Posterior short-segment fixation with or without fusion for thoracolumbar burst fractures. A five to seven-year prospective randomized study. J Bone Joint Surg Am 91:1033-1041, 2009

4. Eck JC: Minimally invasive corpectomy and posterior stabilization for lumbar burst fracture. Spine J 11:904-908, 2011

5. Faciszewski T, Winter RB, Lonstein JE, Denis F, Johnson L: The surgical and medical perioperative complications of anterior spinal fusion surgery in the thoracic and lumbar spine in adults. A review of 1223 procedures. Spine (Phila Pa 1976) 20:1592-1599, 1995

6. Foley KT, Gupta SK, Justis JR, Sherman MC: Percutaneous pedicle screw fixation of the lumbar spine. Neurosurg Focus 10(4):E10, 2001

7. Fuentes S, Blondel B, Metellus P, Gaudart J, Adetchessi T, Du- four H: Percutaneous kyphoplasty and pedicle screw fixation for the management of thoraco-lumbar burst fractures. Eur Spine J 19:1281-1287, 2010

8. Galan TV, Mohan V, Klineberg EO, Gupta MC, Roberto RF, Ellwitz JP: Case report: incisional hernia as a complication of extreme lateral interbody fusion. Spine J 12:e1-e6, 2012

9. Gertzbein SD: Scoliosis Research Society. Multicenter spine fracture study. Spine (Phila Pa 1976) 17:528-540, 1992

10. Grossbach AJ, Dahdaleh NS, Abel TJ, Woods GD, Dlouhy BJ, Hitchon PW: Flexion-distraction injuries of the thoracolumbar spine: open fusion versus percutaneous pedicle screw fixation. Neurosurg Focus 35(2):E2, 2013

11. Gurwitz GS, Dawson JM, McNamara MJ, Federspiel CF, Spengler DM: Biomechanical analysis of three surgical approaches for lumbar burst fractures using short-segment instrumentation. Spine (Phila Pa 1976) 18:977-982, 1993

12. Isaacs RE, Hyde J, Goodrich JA, Rodgers WB, Phillips FM: A prospective, nonrandomized, multicenter evaluation of extreme lateral interbody fusion for the treatment of adult degenerative scoliosis: perioperative outcomes and complications. Spine (Phila Pa 1976) 35 (26 Suppl):S322-S330, 2010

13. Jiang XZ, Tian W, Liu B, Li Q, Zhang GL, Hu L, et al: Comparison of a paraspinal approach with a percutaneous approach in the treatment of thoracolumbar burst fractures with posterior ligamentous complex injury: a prospective randomized controlled trial. J Int Med Res 40:1343-1356, 2012

14. Kaneda K, Taneichi H, Abumi K, Hashimoto T, Satoh S, Fujiya M: Anterior decompression and stabilization with the Kaneda device for thoracolumbar burst fractures associated with neurological deficits. J Bone Joint Surg Am 79:69-83, 1997

15. Kawaguchi Y, Matsui H, Tsuji H: Back muscle injury after posterior lumbar spine surgery. Part 1: histologic and histochemical analyses in rats. Spine (Phila Pa 1976) 19:2590-2597, 1994

16. Kawaguchi $Y$, Matsui $H$, Tsuji $H$ : Back muscle injury after posterior lumbar spine surgery. Part 2: histologic and histochemical analyses in humans. Spine (Phila Pa 1976) 19:2598-2602, 1994

17. Khoo LT, Beisse R, Potulski M: Thoracoscopic-assisted treatment of thoracic and lumbar fractures: a series of 371 consecutive cases. Neurosurgery 51 (5 Suppl):S104-S117, 2002

18. Kim DH, Jahng TA, Balabhadra RS, Potulski M, Beisse R: Thoracoscopic transdiaphragmatic approach to thoracolumbar junction fractures. Spine J 4:317-328, 2004

19. Kim DY, Lee SH, Chung SK, Lee HY: Comparison of multifidus muscle atrophy and trunk extension muscle strength: percutaneous versus open pedicle screw fixation. Spine (Phila Pa 1976) 30:123-129, 2005

20. Konstantinidis L, Mayer E, Strohm PC, Hirschmüller A, Südkamp NP, Helwig P: Early surgery-related complications after anteroposterior stabilization of vertebral body fractures in the thoracolumbar region. J Orthop Sci 15:178-184, 2010

21. Korovessis P, Baikousis A, Zacharatos S, Petsinis G, Koureas G, Iliopoulos P: Combined anterior plus posterior stabilization versus posterior short-segment instrumentation and fusion for mid-lumbar (L2-L4) burst fractures. Spine (Phila Pa 1976) 31:859-868, 2006

22. Korovessis P, Hadjipavlou A, Repantis T: Minimal invasive short posterior instrumentation plus balloon kyphoplasty with calcium phosphate for burst and severe compression lumbar fractures. Spine (Phila Pa 1976) 33:658-667, 2008

23. Kramer DL, Rodgers WB, Mansfield FL: Transpedicular instrumentation and short-segment fusion of thoracolumbar fractures: a prospective study using a single instrumentation system. J Orthop Trauma 9:499-506, 1995

24. Lee JK, Jang JW, Kim TW, Kim TS, Kim SH, Moon SJ: Percutaneous short-segment pedicle screw placement without fusion in the treatment of thoracolumbar burst fractures: is it effective? Comparative study with open short-segment pedicle 


\section{T. Koreckij, D. K. Park, and J. Fischgrund}

screw fixation with posterolateral fusion. Acta Neurochir (Wien) 155:2305-2312, 2013

25. Maestretti G, Cremer C, Otten P, Jakob RP: Prospective study of standalone balloon kyphoplasty with calcium phosphate cement augmentation in traumatic fractures. Eur Spine J 16: 601-610, 2007

26. Martin CT, Witham TF, Kebaish KM: Sacropelvic fixation: two case reports of a new percutaneous technique. Spine (Phila Pa 1976) 36:E618-E621, 2011

27. McCormack T, Karaikovic E, Gaines RW: The load sharing classification of spine fractures. Spine (Phila Pa 1976) 19: 1741-1744, 1994

28. McLain RF, Sparling E, Benson DR: Early failure of shortsegment pedicle instrumentation for thoracolumbar fractures. A preliminary report. J Bone Joint Surg Am 75:162-167, 1993

29. Mermelstein LE, McLain RF, Yerby SA: Reinforcement of thoracolumbar burst fractures with calcium phosphate cement. A biomechanical study. Spine (Phila Pa 1976) 23:664671,1998

30. Mobbs RJ, Raley DA: Complications with K-wire insertion for percutaneous pedicle screws. J Spinal Disord Tech [epub ahead of print], 2013

31. Ni WF, Huang YX, Chi YL, Xu HZ, Lin Y, Wang XY, et al: Percutaneous pedicle screw fixation for neurologic intact thoracolumbar burst fractures. J Spinal Disord Tech 23:530-537, 2010

32. O'Brien JR, Matteini L, Yu WD, Kebaish KM: Feasibility of minimally invasive sacropelvic fixation: percutaneous S2 alar iliac fixation. Spine (Phila Pa 1976) 35:460-464, 2010

33. Park DK, Lee MJ, Lin EL, Singh K, An HS, Phillips FM: The relationship of intrapsoas nerves during a transpsoas approach to the lumbar spine: anatomic study. J Spinal Disord Tech 23:223-228, 2010

34. Parker JW, Lane JR, Karaikovic EE, Gaines RW: Successful short-segment instrumentation and fusion for thoracolumbar spine fractures: a consecutive 4 1/2-year series. Spine (Phila Pa 1976) 25:1157-1170, 2000

35. Patel VC, Park DK, Herkowitz HN: Lateral transpsoas fusion: indications and outcomes. ScientificWorldJournal 2012:893608, 2012

36. Rahamimov N, Mulla H, Shani A, Freiman S: Percutaneous augmented instrumentation of unstable thoracolumbar burst fractures. Eur Spine J 21:850-854, 2012

37. Raley DA, Mobbs RJ: Retrospective computed tomography scan analysis of percutaneously inserted pedicle screws for posterior transpedicular stabilization of the thoracic and lumbar spine: accuracy and complication rates. Spine (Phila $\mathbf{P a}$ 1976) 37:1092-1100, 2012

38. Rantanen J, Hurme M, Falck B, Alaranta H, Nykvist F, Lehto $\mathrm{M}$, et al: The lumbar multifidus muscle five years after surgery for a lumbar intervertebral disc herniation. Spine (Phila Pa 1976) 18:568-574, 1993

39. Regev GJ, Lee YP, Taylor WR, Garfin SR, Kim CW: Nerve injury to the posterior rami medial branch during the insertion of pedicle screws: comparison of mini-open versus percutaneous pedicle screw insertion techniques. Spine (Phila Pa 1976) 34:1239-1242, 2009

40. Rodgers WB, Gerber EJ, Patterson J: Intraoperative and early postoperative complications in extreme lateral interbody fusion: an analysis of 600 cases. Spine (Phila Pa 1976) 36:2632,2011

41. Smith WD, Dakwar E, Le TV, Christian G, Serrano S, Uribe
JS: Minimally invasive surgery for traumatic spinal pathologies: a mini-open, lateral approach in the thoracic and lumbar spine. Spine (Phila Pa 1976) 35 (26 Suppl):S338-S346, 2010

42. Tomycz L, Parker SL, McGirt MJ: Minimally invasive transpsoas L2 corpectomy and percutaneous pedicle screw fixation for osteoporotic burst fracture in the elderly: technical report. J Spinal Disord Tech [epub ahead of print], 2012

43. Vanek P, Bradac O, Konopkova R, de Lacy P, Lacman J, Benes $\mathrm{V}$ : Treatment of thoracolumbar trauma by short-segment percutaneous transpedicular screw instrumentation: prospective comparative study with a minimum 2-year follow-up. Clinical article. J Neurosurg Spine 20:150-156, 2014

44. Verlaan JJ, Dhert WJ, Verbout AJ, Oner FC: Balloon vertebroplasty in combination with pedicle screw instrumentation: a novel technique to treat thoracic and lumbar burst fractures. Spine (Phila Pa 1976) 30:E73-E79, 2005

45. Verlaan JJ, Diekerhof CH, Buskens E, van der Tweel I, Verbout AJ, Dhert WJ, et al: Surgical treatment of traumatic fractures of the thoracic and lumbar spine: a systematic review of the literature on techniques, complications, and outcome. Spine (Phila Pa 1976) 29:803-814, 2004

46. Wang H, Li C, Zhou Y, Zhang Z, Wang J, Chu T: Percutaneous pedicle screw fixation through the pedicle of fractured vertebra in the treatment of type A thoracolumbar fractures using Sextant system: an analysis of 38 cases. Chin J Traumatol 13:137-145, 2010

47. Wang MY, Ludwig SC, Anderson DG, Mummaneni PV: Percutaneous iliac screw placement: description of a new minimally invasive technique. Neurosurg Focus 25(2):E17, 2008

48. Wang ST, Ma HL, Liu CL, Yu WK, Chang MC, Chen TH: Is fusion necessary for surgically treated burst fractures of the thoracolumbar and lumbar spine? A prospective, randomized study. Spine (Phila Pa 1976) 31:2646-2653, 2006

49. Wiesner L, Kothe R, Schulitz KP, Rüther W: Clinical evaluation and computed tomography scan analysis of screw tracts after percutaneous insertion of pedicle screws in the lumbar spine. Spine (Phila Pa 1976) 25:615-621, 2000

50. Wild MH, Glees M, Plieschnegger C, Wenda K: Five-year follow-up examination after purely minimally invasive posterior stabilization of thoracolumbar fractures: a comparison of minimally invasive percutaneously and conventionally open treated patients. Arch Orthop Trauma Surg 127:335-343, 2007

51. Wood K, Buttermann G, Mehbod A, Garvey T, Jhanjee R, Sechriest V: Operative compared with nonoperative treatment of a thoracolumbar burst fracture without neurological deficit. J Bone Joint Surg Am 85-A:773-781, 2003 (Erratum in J Bone Joint Surg Am 86-A:1283, 2004)

52. Yang H, Shi JH, Ebraheim M, Liu X, Konrad J, Husain I, et al: Outcome of thoracolumbar burst fractures treated with indirect reduction and fixation without fusion. Eur Spine J 20: 380-386, 2011

Manuscript submitted March 9, 2014

Accepted May 1, 2014.

Please include this information when citing this paper: DOI: 10.3171/2014.5.FOCUS1494.

Address correspondence to: Jeffrey Fischgrund, M.D., 3535 W. 13 Mile Rd., Royal Oak, MI 48073. email: jsfischgrund@comcast. net. 